\title{
Vulnerability of coastal communities to sea-level rise: a case study of Cape May County, New Jersey, USA
}

\author{
Shuang-Ye Wu ${ }^{1, *}$, Brent Yarnal $^{1}$, Ann Fisher ${ }^{2}$ \\ ${ }^{1}$ Department of Geography and Center for Integrated Regional Assessment and ${ }^{2}$ Department of Agricultural Economics \& \\ Rural Sociology and Center for Integrated Regional Assessment, The Pennsylvania State University, University Park, \\ Pennsylvania 16802, USA
}

\begin{abstract}
This study demonstrates how sea-level rise increases the vulnerability of coastal communities to flooding associated with coastal storms. The case study applies a GIS-based methodology to assess the vulnerability of Cape May County, New Jersey, to flood hazards caused by both riverine flooding and coastal storm surges. For storm events of differing intensities, it first identifies areas that will be inundated and how they will change with projected sea-level rise. It then assesses the social vulnerability of the county, taking into account factors such as age, gender, race, income and housing conditions. Finally, it combines physical and social vulnerabilities to create a picture of the county's present overall vulnerability, as well as how this will change with projected sea-level rise. To account for uncertainties in projections, possible ranges of both population growth and sea-level rise are incorporated in low, medium and high scenarios. The results show that sea-level rise will increase the vulnerability of the county to flood hazards considerably by increasing the areas that are exposed to the highest flood risk, hence increasing the number of critical facilities, properties, and people to the risk of flooding. Comparing the upper- and lower-bound scenarios indicates that poorly managed development could increase the county's vulnerability to flooding. These results suggest that decision-makers could reduce vulnerability by making choices that steer development away from highrisk areas.
\end{abstract}

KEY WORDS: Vulnerability assessment $\cdot$ Coastal hazards $\cdot$ Sea-level rise $\cdot$ Climate change impacts Climate change scenarios $\cdot$ Coastal development

\section{INTRODUCTION}

Climate change is expected to cause global, regional, and local changes in many elements of the climate system (IPCC 1998). Some of the projected climate changes and their associated impacts imply important ramifications for coastal communities. Accelerated sea-level rise, increased frequency and intensity of coastal and inland storms, and more riverine flooding because of increased precipitation would exacerbate the already considerable vulnerability of coastal communities to natural hazards (IPCC 2001).

*E-mail: shuangyew@yahoo.com
Several recent studies have addressed the vulnerability of United States coastal communities to contemporary natural hazards, especially extreme coastal storms (Clark et al. 1998, David et al. 1999, Mileti 1999, Morrow 1999, Cutter et al. 2000, H. John Heinz III Center for Science, Economics and the Environment 2000). Most of these studies noted that climate change would affect the vulnerability of coastal communities, but none of them had a research design that directly addresses the impacts of climate change. Yet, despite great uncertainties about the impacts of climate change in specific regions and locales, experts usually regard sea-level rise as the most certain consequence of climate change (IPCC 1996). Such projections have particular relevance to coastal communities because- 
even if storminess remains unchanged-sea-level rise will increase the level of storm surge and the area affected by coastal flooding, implying more damage from future coastal storms with intensities similar to present-day storms.

This study examines the vulnerability of one particular United States coastal community-Cape May County, New Jersey-to flooding and how that flooding will change with the projected sea-level rise. The study goes beyond mere local interest, however. It provides insight to the limited but growing body of knowledge on how climate change will affect coastal flood hazards. It contributes to the literature on the social construction of vulnerability to natural hazards and climate change. Finally, it establishes a GIS-based methodology for the quantitative assessment of vulnerability.

Five main sections follow this introduction. Section 2 reviews the concept of vulnerability. Section 3 briefly describes the study area-Cape May County. Section 4 summarizes the county's historical encounters with major coastal storms and its current vulnerability to storm hazards. Section 5 quantitatively assesses the county's present physical exposure and social vulnerability to storm flooding and the projected changes in exposure and vulnerability resulting from sea-level rise. Low, medium, and high scenarios of sea-level rise and population growth account for uncertainty in the projections. Section 6 concludes that, although Cape May County and other places are particularly vulnerable to climate change-enhanced flooding, effective development planning can reduce vulnerability.

\section{MEANINGS OF VULNERABILITY}

Vulnerability is an essential concept in humanenvironment research. Dow (1992), Dow \& Downing (1995), Cutter (1996), Alexander (1997), and Hewitt (1997) have provided excellent reviews of major literature on the development of the concept. Broadly speaking, vulnerability is the potential for loss (Cutter 1996), but the definition varies with topic (e.g. hazards, disasters, or risk assessment) and with discipline (e.g. geography, sociology, or political science). Despite this diversity, there are 2 dominant perspectives in conceptualizing vulnerability. The first identifies vulnerability with the potential exposure to a physical hazard. Studies from this perspective focus on the distributions of hazardous conditions and on the ways that these conditions affect people and structures. For example, as early as 1977, the United Nations Disaster Relief Organization (UNDRO) defined vulnerability as natural hazard risk (the probability that an event will occur) multiplied by damage potential (the likely damage that will result if the event occurs) (UNDRO 1977). Green
(1990) reviewed community infrastructure vulnerable to flooding, such as water supply, transportation, electricity, water treatment and sewage, and telecommunication systems. In her discussion of global environmental change, Liverman (1990a) related people's vulnerability to the disruption of global biophysical processes. Variables used to assess such physical vulnerability normally include proximity to the source of threat, incident frequency or probability, and magnitude, duration, or spatial impact of particular hazards (Hewitt \& Burton 1971, Heyman et al. 1991, Haque \& Blair 1992, Quarantelli 1992, Alexander 1993).

The second perspective on vulnerability takes exposure as given and searches for the patterns of differential losses among people affected. The studies following this approach focus on potential coping ability of individuals or communities, including the ability to withstand the damaging effect of a hazard (i.e. resistance) and the ability to recover quickly from the damage caused by a hazard (i.e. resilience) (Susman et al. 1983, Bogard 1989, Chambers 1989, Anderson \& Woodrow 1991, Downing 1991, 1992, Watts \& Bohle 1993, Blaikie et al. 1994, Bohle et al. 1994, Chen 1994, Yarnal 1994, Hewitt 1997, Clark et al. 1998). This perspective highlights the social construction of vulnerability. A wide variety of variables are examined as indicators of such social vulnerability, including gender (Enarson \& Morrow 1998), age (Bolin \& Klenow 1983), disability (Parr 1987), family structure and social networks (Drabek \& Key 1986), housing and built environment (Bolin \& Stanford 1991, Quarantelli 1991), income and material resources (Bolin \& Stanford 1991), and race and ethnicity (Bolin \& Bolton 1986, Fothergill et al. 1999). As pointed out by Cutter (1996), although the vulnerability indicators are often single variables, they are manifestations of multidimensional factors such as institutional development, social relations, or political power. A subset of studies examining social vulnerability go beyond the assessment of vulnerability indicators and aim to explain how the vulnerable conditions are rooted in historical, cultural, social, and economic processes that impinge on the individual's or society's ability to cope with disasters and to respond to them (Watts \& Bolhe 1993, Blaikie et al. 1994).

Based on these 2 prevailing trends in the literature, Cutter (1996) and Cutter et al. (2000) formalized a third approach - vulnerability of places - in which vulnerability is both a biophysical risk and a social response, but within a specific geographic domain. Many researchers have used, implicitly or explicitly, this integrative approach in a wide array of spatial contexts, ranging from national to local (Liverman 1986, 1990b, Blaikie \& Brookfield 1987, Lewis 1987, 1990, Wilhite \& Easterling 1987, Mitchel et al. 1989, Palm \& Hodgson 1992, Degg 1993, Longhurst 1995, Clark et al. 1998). 


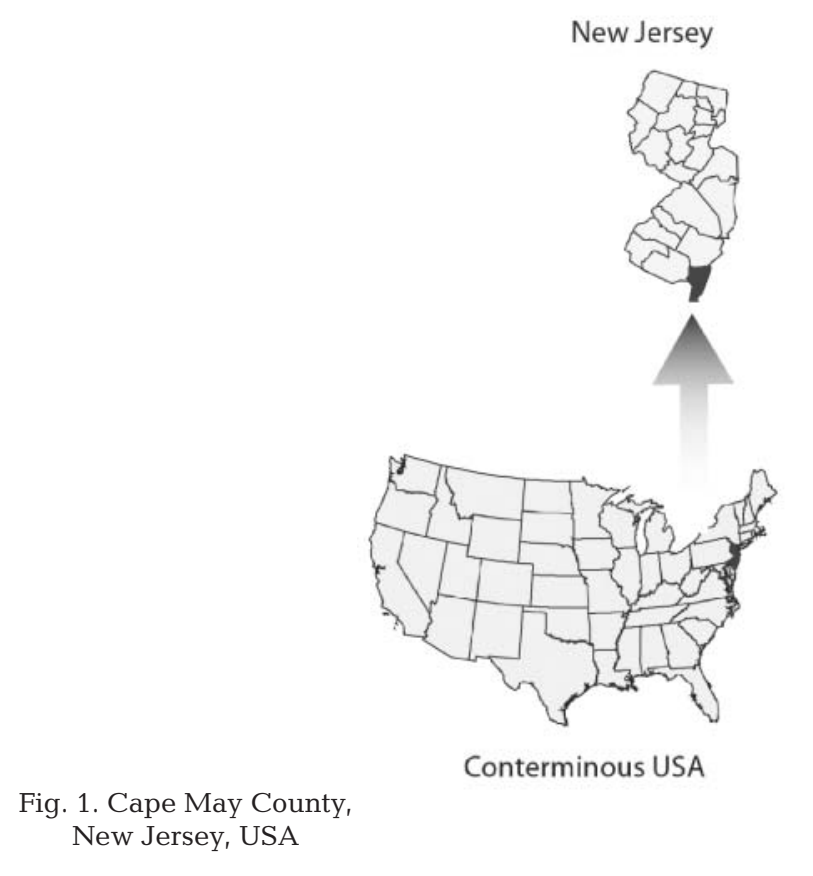

This study adopts the vulnerability of places framework to examine potential exposure and coping abilities in Cape May County. It examines, first, the spatial distribution of present flood risk within the county, taking into consideration both inland riverine flooding and coastal flooding as a result of storm surge, and, second, the distribution of land use, people, and facilities within different flood-risk zones. It goes on to analyze how the distribution of flood risk will change with projections of sea-level rise and how the exposure of population and facilities to flooding consequently will change. Taking exposure as an initial measure of vulnerability is a useful first step because it is relatively easy to measure and it captures some indicative patterns in distribution (Dow 1992). However, mapping the exposure alone does not capture the pattern of differentiated coping abilities among the population exposed to hazards. Therefore, to obtain a more accurate picture of potential human suffering, this study examines indicators of social vulnerability, such as gender, age, wealth, house ownership, and family structure, and how these indicators correspond with flood-risk zones both at present and with projected sea-level rise.

\section{STUDY AREA}

Cape May County is located in southern New Jersey, where it is bordered by the Atlantic Ocean on the east and Delaware Bay on the west (Fig. 1). It lies entirely within the Coastal Plain physiographic province, an area

\section{Cape May County}

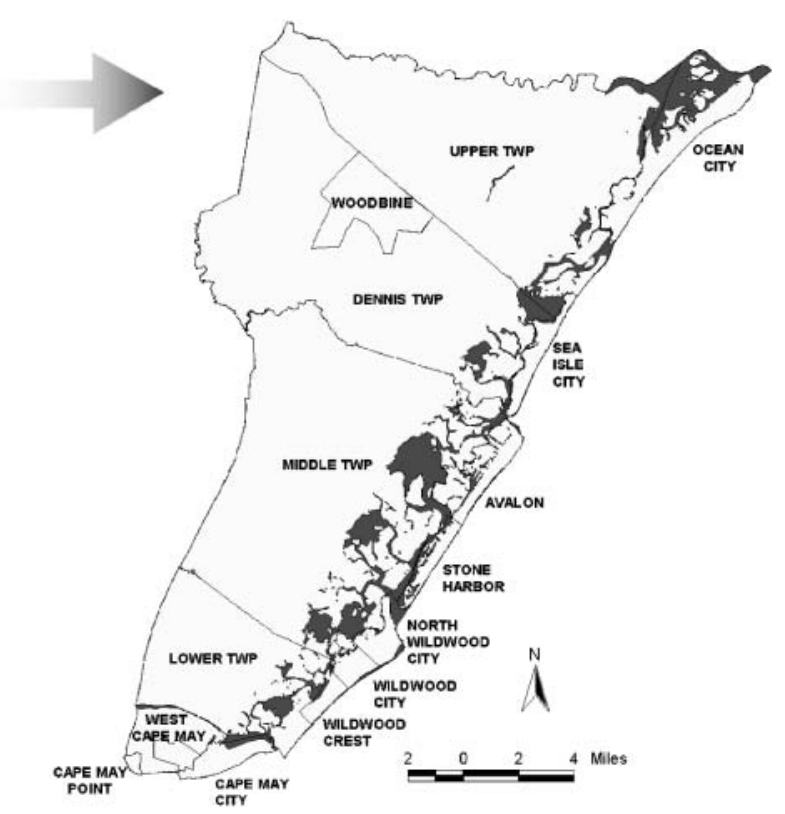

characterized by very low topographic relief. Along the county's Atlantic coast, there are elongated, flat-lying barrier islands broken by tidal inlets and separated from the mainland by saltwater lagoons and marshes (Fig. 2).

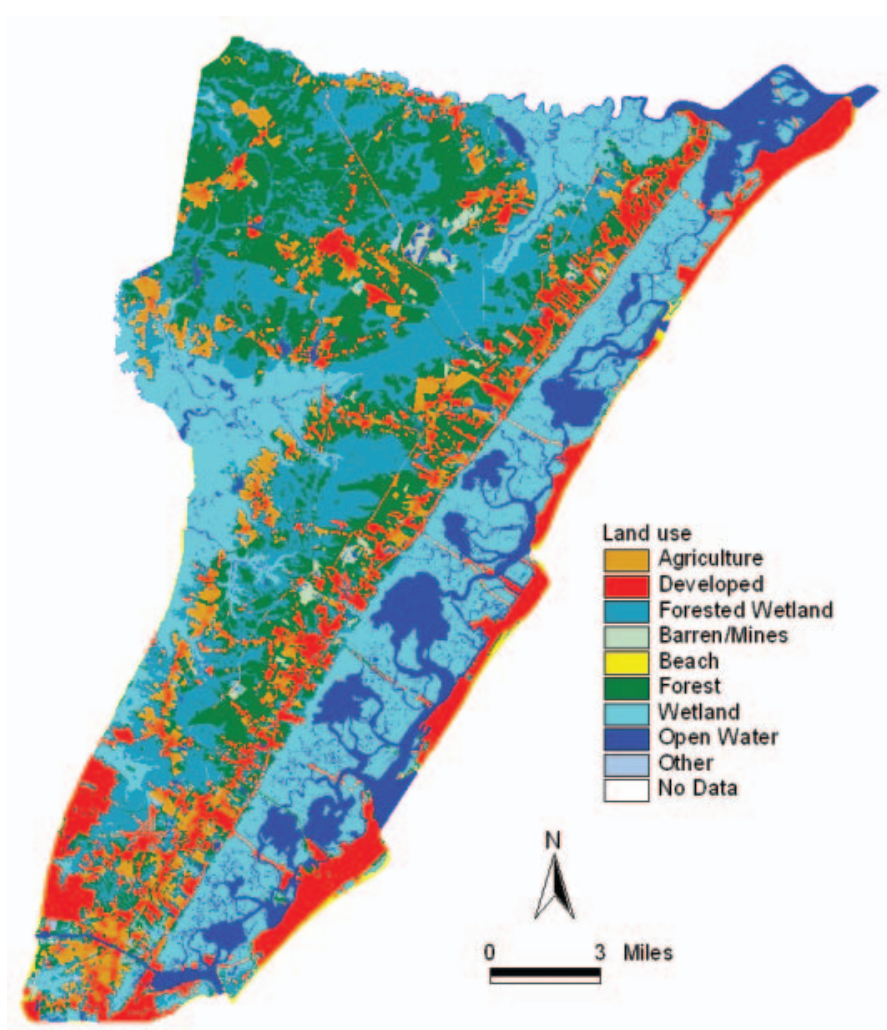

Fig. 2. Land use/land cover of Cape May County 
Barrier island systems are highly dynamic, constantly changing their shapes and beach widths on a daily, seasonal, and annual basis, especially in response to coastal storms. On the mainland, elevations are highest in a zone running from southwest to northeast and extending into the northwestern part of the county, but are at most only a few meters above sea level and are usually much lower. Although the sandy soils are extremely well drained and promote pine forests, in many places the water table is close to the surface and gives rise to wetlands and ponds, even in areas with higher elevations. The Delaware Bay coast is dominated by extensive wetlands, except in the extreme southwest. The many lagoons, marshes, and wetlands promote a large, diverse bird population.

Cape May City (Fig. 1) claims to be the nation's oldest seashore resort town, so the county's history of the last 2 centuries is influenced strongly by tourism. Besides typical coastal tourist activities, bird watching is an essential element of the local economy. Land use is determined by tourism and zoning ordinances that vary across localities. The barrier islands and many parts of the mainland are highly developed (Fig. 2), with an assortment of vacation homes, bed-and-breakfast establishments, hotels, and businesses providing entertainment and tourism services. Year-round residents and businesses designed to service permanent residents tend to locate on the cheaper, higher ground of the mainland. Some year-round residents live in non-incorporated communities (not shown) along the Delaware Bay between the incorporated areas near the cape and the wetland areas to the north. Socioeconomic levels vary substantially, with housing prices ranging from modest apartments and single-family homes worth $<\$ 10^{5}$ in non-incorporated parts of the mainland to showy homes valued at $>\$ 10^{6}$ on the barrier islands and in Cape May City.

\section{EXPOSURE OF CAPE MAY COUNTY TO COASTAL STORMS}

Hurricanes and strong extratropical coastal storms have a powerful influence on Cape May County, where their winds, waves, and precipitation produce coastal floods and have a wide range of other impacts, such as shoreline erosion, loss of vegetation, floating debris, and soil salinization. These effects could increase in the future.

The frequency at which major hurricanes pass Cape May is less than that for the more southerly Atlantic coast states and coastal areas in the Gulf of
Mexico (Elsner \& Kara 1999). On average, 1 tropical cyclone passes within $100 \mathrm{~km}$ of Cape May every $4.5 \mathrm{yr}$ (Table 1). In 1999, Tropical Storm Floyd, with $30 \mathrm{~m} \mathrm{~s}^{-1}$ winds and heavy flooding inland, was the last tropical system to hit Cape May County; coastal damage was light. The last major hurricane to make direct landfall in Cape May County was the Category 4 (on the SaffirSimpson scale of hurricane intensity, Table 2) Great Norfolk-Long Island Hurricane of September 1821 (Ludlum 1963, Bentley \& Horstmeyer 1999). The damage was catastrophic, but records are inadequate and development was too limited to permit direct comparison to 20th- and 21st-century storms. Despite the absence of landfalling hurricanes since then, some hurricanes have passed nearby and generated significant coastal flooding and damage. For example, the Chesapeake-Potomac Hurricane of August 1933 passed inland to the west of Cape May but resulted in easterly winds that piled water along the coast for days, causing it to run nearly $2 \mathrm{~m}$ deep over the barrier islands during high tide (Cobb 1991). The Category 4 (perhaps Category 5) Great Atlantic Hurricane of September 1944 pushed tides to $2.9 \mathrm{~m}$ above normal and produced a storm surge estimated by some Cape May residents to have been $12 \mathrm{~m}$ (Savadore \& Bucholz 1993).

Extratropical coastal storms-commonly called northeasters or nor'easters in the region-are much more frequent than tropical systems, but create equivalent damage along the coastal zone (Dolan \& Davis 1992, Davis \& Dolan 1993; see Table 3). For instance, the Category V nor'easter known as the Ash Wednesday storm of March 1962 (Watson 2001) stalled off the New Jersey coast for $3 \mathrm{~d}$, coinciding with several spring equinox high tides and causing 10 deaths and hundreds of millions of dollars in damage along the New Jersey coast (Savadore \& Bucholz 1993). Although data from 1942-1984 peg the return intervals-average durations between successive storms - of Category IV and Category V nor'easters at 11 and 67 yr, respectively (Dolan et al. 1988), one of these storm categories

Table 1. Tropical cyclones passing within $100 \mathrm{~km}$ of Cape May since 1870. Source: Hurricanecity (2001)

\begin{tabular}{|c|c|c|c|}
\hline & Seaward of Cape May & Inland of Cape May & Direct hit \\
\hline Tropical & $1881^{\mathrm{a}}, 1925,1992$ & $1874,1877,1881^{\mathrm{a}}$ & 1893, 1897, 1955, \\
\hline Storm & $1996^{\mathrm{a}}$ & $\begin{array}{l}\text { 1882, 1889, 1894, } \\
1918,1935,1960 \\
1996^{\mathrm{a}}\end{array}$ & $1967,1971,1999$ \\
\hline Hurricane & $\begin{array}{l}1888^{a}, 1893^{a}, 1899 \\
1933(2), 1936,1944 \\
1953,1960,1985\end{array}$ & $1888^{\mathrm{a}}, 1893^{\mathrm{a}}$ & \\
\hline \multicolumn{4}{|c|}{$\begin{array}{l}\text { aStorm crossed inland, then emerged over water south of Cape May, and } \\
\text { finally passed east of Cape May }\end{array}$} \\
\hline
\end{tabular}


Table 2. The Saffir-Simpson hurricane classification scale and some related effects. Sources: NHC (1999a) and Guard \& Lander (1999)

\begin{tabular}{|cccc|}
\hline Category & $\begin{array}{c}\text { Wind speed } \\
\left(\mathrm{m} \mathrm{s}^{-1}\right)\end{array}$ & $\begin{array}{c}\text { Average storm } \\
\text { surge }(\mathrm{m})\end{array}$ & $\begin{array}{c}\text { Breaking waves in } \\
\text { protected bays }(\mathrm{m})\end{array}$ \\
\hline 1 & $33-42$ & $1.2-1.8$ & $1.5-2.1$ \\
2 & $43-49$ & $1.8-2.7$ & $2.1-2.7$ \\
3 & $50-58$ & $2.7-3.9$ & $3.3-4.2$ \\
4 & $59-69$ & $3.9-5.5$ & $4.5-7.3$ \\
5 & $>69$ & $>5.5$ & $>9.2$ \\
& & & \\
\hline
\end{tabular}

has occurred on average once per year since then. Recent Category V nor'easters include the March 1989 coastal storm (Dolan et al. 1990) and the Halloween storm of 1991 (made famous by the novel and movie, 'The Perfect Storm'; Davis \& Dolan 1992).

Nor'easters are not 'wintertime' hurricanes and the pattern of their destructiveness differs from that of their tropical cousins (Table 4). Nor'easters cause their damage not by absolute wind strength, but by the interaction of wind strength with size, longevity, and fetch; that is, to cause great damage, a nor'easter must be large, must last for several days, and must blow over a broad stretch of ocean (Davis \& Dolan 1993). Because its winds are usually less than hurricane strength (Table 2), a nor'easter's overall damage tends to be restricted to the coastal zone. In contrast, damage from hurricanes often extends a considerable distance inland. Nevertheless, because nor'easters are large, their coastal damage is widespread and extends hundreds to thousands of $\mathrm{km}$ along the shoreline of the US East Coast; coastal damage from hurricanes is usually more concentrated, extending $10 \mathrm{~s}$ to $100 \mathrm{~s}$ of $\mathrm{km}$ along the shore. Nor'easters' waves are at their maximum when the center of the storm is a considerable distance offshore, therefore the associated precipitation can be light to non-existent; precipitation from hurricanes is often great $\left(\sim 10^{2} \mathrm{~mm}\right)$ when the waves are at their maximum because the eye of the storm is nearby. Damage from nor'easters is greatest when the storm is slow-moving or stalls and therefore exists for days, while damage from hurricanes can be large for either slow-moving or fast-moving storms. Finally, almost all of the damage caused by nor'easters results from wave action, but the greatest damage caused by hurricanes results from wind damage and storm surge.

The relatively infrequent occurrence of tropical cyclones, and, until recently, severe and extreme nor'easters, generates a false sense of security among residents and visitors to Cape May County. For example, Nordstrom et al. (1986) pointed out that by the mid-1980s many had forgotten the damages associated with the Ash Wednesday storm. New houses were built in locations where homes had been swept awaythe same locations that the storm had revealed to be the most hazardous. Hence, when powerful coastal

Table 3. The Dolan-Davis nor'easter intensity scale and related impacts. Source: Dolan \& Davis (1992)

\begin{tabular}{|c|c|c|c|c|c|}
\hline Storm class & Return interval & Beach erosion & Dune erosion & Overwash & Property damage \\
\hline I (Weak) & $3 \mathrm{~d}$ & Minor changes & None & No & No \\
\hline II (Moderate) & $12 \mathrm{~d}$ & $\begin{array}{l}\text { Modest; mostly } \\
\text { to lower beach }\end{array}$ & Minor & No & Modest \\
\hline III (Significant) & $9 \mathrm{mo}$ & $\begin{array}{l}\text { Erosion extends } \\
\text { across beach }\end{array}$ & Can be significant & No & $\begin{array}{l}\text { Loss of many struc- } \\
\text { tures at local level }\end{array}$ \\
\hline IV (Severe) & $11 \mathrm{yr}$ & $\begin{array}{l}\text { Severe beach erosion } \\
\text { and recession }\end{array}$ & $\begin{array}{l}\text { Severe dune erosion } \\
\text { or destruction }\end{array}$ & $\begin{array}{l}\text { On low } \\
\text { beaches }\end{array}$ & $\begin{array}{l}\text { Loss of structures at } \\
\text { community scale }\end{array}$ \\
\hline V (Extreme) & $67 \mathrm{yr}$ & $\begin{array}{l}\text { Extreme beach } \\
\text { erosion }\end{array}$ & $\begin{array}{l}\text { Dunes destroyed } \\
\text { over extensive areas }\end{array}$ & $\begin{array}{l}\text { Massive, in } \\
\text { sheets and } \\
\text { channels }\end{array}$ & $\begin{array}{l}\text { Extensive at } \\
\text { regional-scale; } \\
\text { millions of dollars }\end{array}$ \\
\hline
\end{tabular}

Table 4. Comparison of relative coastal damage potential of nor'easters and tropical cyclones

\begin{tabular}{|c|c|c|}
\hline $\begin{array}{l}\text { Coastal damage } \\
\text { potential }\end{array}$ & Nor'easters & Tropical cyclones \\
\hline Ranked by cause & (1) Wave action, (2) storm surge & $\begin{array}{l}\text { (1) Wind and storm surge, } \\
\text { (2) precipitation, (3) wave action }\end{array}$ \\
\hline Location of damage & Tends to be restricted to coastal zone & Can extend far inland \\
\hline Geographical extent & Hundreds to thousands of $\mathrm{km}$ of shoreline & Tens to hundreds of $\mathrm{km}$ of shoreline \\
\hline $\begin{array}{l}\text { Precipitation when coastal } \\
\text { damage potential is greatest }\end{array}$ & Modest to zero (storm center offshore) & $\begin{array}{l}\text { Zero to great (storm center stalls offshore } \\
\text { - zero; storm passes nearby - great) }\end{array}$ \\
\hline Relationship to storm speed & Great if slow moving & Great, no matter what speed \\
\hline
\end{tabular}


storms hit again, e.g. the October 1991 'Perfect Storm' (Davis \& Dolan 1992), they wreaked havoc in Cape May County.

Damage to structures and property also can result from smaller storms (Nordstrom et al. 1986). For example, Category III storms in December 1974, February 1978, October 1980, and March 1984, to name but a few, caused millions of dollars of damage. Nordstrom et al. (1986) estimated that 56 moderate storms produced significant damage to the New Jersey shore from 1921 to 1962 . With more extensive, dense, and expensive development, the average costs of storm damage rise each year.

Thus, although Cape May County has a lower probability of receiving a direct strike from a hurricane than United States coastal areas at lower latitudes, and has roughly equal probabilities of suffering the effects of a nor'easter as other East Coast states (Dolan \& Davis 1992), a combination of factors makes it highly vulnerable to damage and losses from coastal storms. These factors include dense shorefront development with little physical protection, disproportionately large numbers of temporary residents and day visitors during the summer hurricane season, and limited experience of residents and visitors with severe tropical and extratropical coastal storms.

Projected sea-level rise could further increase the vulnerability of Cape May County to coastal storms. Sea-level rise is a considerable problem in this section of the Mid-Atlantic region coast, with an estimated rate of 3 to $4 \mathrm{~mm} \mathrm{yr}^{-1}$ (Fisher et al. 2000). In addition to the component of relative sea-level rise expected because of climate change (1.0 to $2.5 \mathrm{~mm} \mathrm{yr}^{-1}$ ), a nearly equal amount is the result of subsidence produced by isostatic adjustments (Walker \& Coleman 1987) and other local processes. Given the exceptionally low relief of the county, especially on the barrier islands, this relatively large rate of sea-level rise has the potential to cause much more extensive flooding when future coastal storms strike because the storm surge will start from a higher base.

Moreover, sea-level rise has caused rapid coastal erosion, leading to significant social and economic costs (Leatherman 2001). Shoreline retreat of hundreds of meters has occurred along portions of Cape May County's Atlantic coastline during the last 2 centuries, including some fully developed and inhabited areas (Nordstrom 2000). Since the 1930s, groins, beach nourishment, dune construction, and seawall fortification have been the chief responses to these losses, but because of continued coastal erosion, today 'there is virtually no buffer to deal with forces due to storm events' (US Army Corps of Engineers 2001). As local officials put it, 'We have finally reached a point where we no longer have beaches to erode' (Nordstrom et al.
1986, p. 39). The rapid erosion has diminished the buffering area and hence made people more susceptible to storm damage. To make matters worse, unlike many other areas along the US Atlantic coast, most buildings in Cape May County are not elevated to diminish the likelihood of damage caused by coastal flooding.

In short, coastal storms can cause considerable damage to man-made structures and are a risk to the human life, infrastructure, and economy of Cape May County. Future sea-level rise will exacerbate these risks.

\section{VULNERABILITY ASSESSMENT OF CAPE MAY COUNTY}

With the preceding overview in mind, in this section we analyze the county's vulnerability to storm-related flooding by applying a GIS-based methodology. We also assess how climate change, in particular the sealevel rise projected for this area, will exacerbate its vulnerability.

\subsection{Present and future exposure}

\subsubsection{Flood-risk zones}

Storm surge-water pushed toward the shore by the force of the winds swirling around a storm-poses the greatest potential for damage from a coastal storm (NHC 1999b). Storm surge height is directly related to the intensity of the storm. This advancing surge combines with the normal tide to create the storm tide, which can increase the mean water level by over $4 \mathrm{~m}$. In addition, wind-driven waves are superimposed on the storm tide. The total rise in water level causes severe flooding in coastal areas, particularly when the storm tide coincides with the normal high tide. Much of densely populated Cape May County lies less than $3 \mathrm{~m}$ above mean sea level, so the risk of storm surge is high.

One tool used to evaluate the threat from storm surge is the SLOSH model run by the National Hurricane Center (NHC). SLOSH (Sea, Lake and Overland Surges from Hurricanes) estimates storm surge heights and winds resulting from historical, hypothetical, or predicted hurricanes by taking into account atmospheric pressure, storm size, forward speed, track, and winds (NHC 1999b). The calculations are applied to a specific locale's shoreline, incorporating the unique bay and river configurations, water depths, bridges, roads, and other physical features. The NHC has divided the Atlantic and Pacific coast into $38 \mathrm{SLOSH}$ 
basins and has produced model output for each of them. The SLOSH model output has 4 gridded layers that represent the estimated storm surge height for hurricanes of intensities on the Saffir-Simpson scale 1 to 4. In this study, we used SLOSH model output for the Delaware Bay SLOSH basin produced by the NHC in October 2000 and distributed to local emergency managers.

We compared the SLOSH model output with a digital elevation model (DEM) of Cape May County obtained from the New Jersey Department of Environmental Protection (NJDEP). The DEM has $100 \mathrm{ft}(\sim 30 \mathrm{~m})$ cells and elevation values expressed in integer feet. It was clipped to approximate the county boundary. We mapped the areas where the SLOSH model output projects a storm surge height greater than the elevation. This method identifies the approximate areas inundated by storm surges associated with the various categories of hurricanes and with other coastal storms of comparable intensities (Table 5). The low-risk zone represents areas unlikely to be affected by storm surges.

Inland riverine flooding also poses substantial risk to Cape May County and, because of the considerable rain that can fall during coastal storms, may exacerbate the flooding caused by surges. Based on the Q3 flood data provided by the Federal Emergency Management Agency (FEMA 1996), the county is divided into 4 risk zones, which are the V Zone (the velocity zone, where both wind and wave action occur with flooding), the $100 \mathrm{yr}$ flood plain (where a severe flood is expected once in $100 \mathrm{yr}$ ), the $500 \mathrm{yr}$ flood plain (where a severe flood is expected once in $500 \mathrm{yr}$ ), and the low-risk zone (where flooding is not likely to happen). The amount of land area covered under each category is summarized in Table 6. It can be seen that half of the county can expect serious flooding at least once in $100 \mathrm{yr}$.

To develop a picture of combined riverine and coastal flood risk, we calculated the area affected by the 4 hazard categories associated with riverine flooding and by the 5 hazard categories related to coastal flooding. We assigned to each of the mapped hazard categories a score according to its degree of risk ranging from 1 to 5 for coastal flooding and from 1 to 4 for riverine flooding (Tables 5 \& 6). Finally, we combined the 2 layers by adding the risk score of each layer and then divided the summary score evenly into 4 floodrisk categories: very high, high, moderate, and low risk (Table 7). The distribution of present-day combined flood risk for Cape May County is presented in Fig. 3 and summarized in Table 8.

Climate change has many direct consequences on flood risk in coastal communities. On the one hand, there are still large uncertainties in many of the potential impacts on coastal storms, such as storm frequency, storm intensity, and storm track. On the other hand,

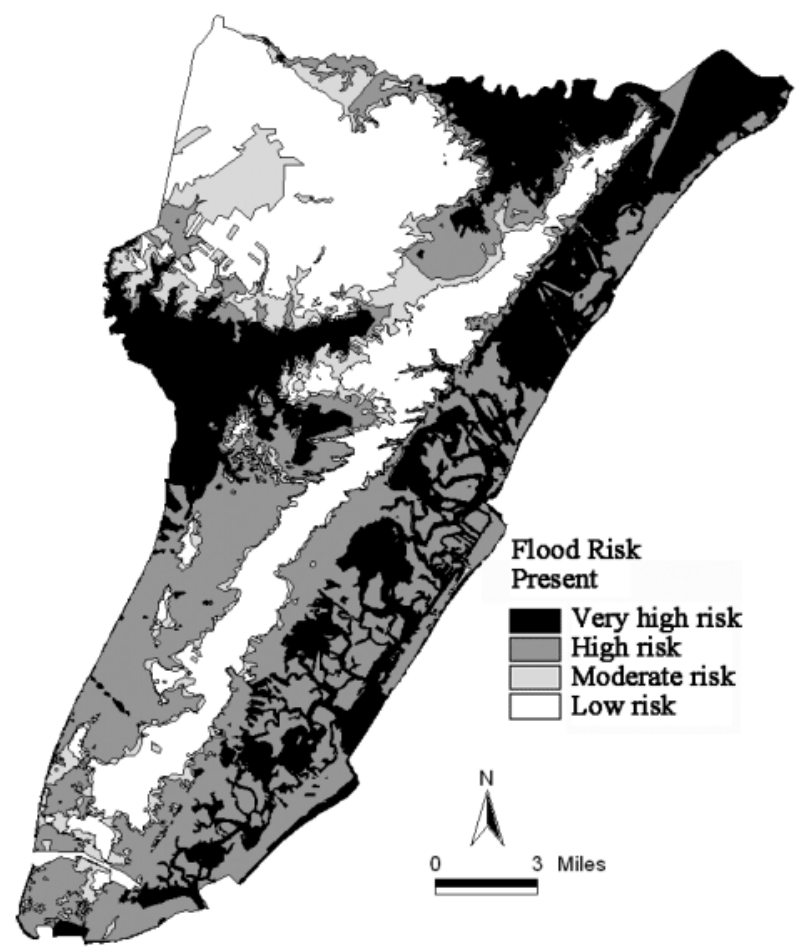

Fig. 3. Distribution of present flood risk zones

the most certain and direct impact comes from sealevel rise. Other things being equal, a storm occurring with elevated sea level would cause more damage than one of same intensity occurring with lower sea level. As part of the Mid-Atlantic Regional Assessment (MARA) of the potential impacts of climate change (Fisher et al. 2000), Najjar et al. (2000) estimated that the most likely scenario for the Mid-Atlantic coast

Table 5. Areas susceptible to storm surge flooding and their risk scores

\begin{tabular}{|lccc|}
\hline Storm surge category & Area $\left(\mathrm{km}^{2}\right)$ & Percentage & Risk score \\
\hline Category 1 & 189.4 & 26.16 & 5 \\
Category 2 & 409.6 & 56.77 & 4 \\
Category 3 & 499.2 & 69.42 & 3 \\
Category 4 & 583.7 & 80.99 & 2 \\
Low risk & 135.7 & 19.01 & 1 \\
Total & 719.4 & 100 & \\
\hline
\end{tabular}

Table 6. Riverine flood zone areas and their risk scores

\begin{tabular}{|lccc|}
\hline Flood zone & Area $\left(\mathrm{km}^{2}\right)$ & Percentage & Risk score \\
\hline V zone & 41 & 5.64 & 4 \\
100 yr floodplain & 361 & 50.14 & 3 \\
500 yr floodplain & 64 & 8.77 & 2 \\
Low risk & 256 & 35.44 & 1 \\
Total & 719 & 100 & \\
\hline
\end{tabular}


Table 7. Scores for combined flood-risk zones

\begin{tabular}{|lc|}
\hline Risk category & Summary scores \\
\hline Very high & $8-9$ \\
High & $6-7$ \\
Moderate & $4-5$ \\
Low & $2-3$ \\
\hline
\end{tabular}

Table 8. Combined flood-risk areas

\begin{tabular}{|lccr|}
\hline Risk category & $\begin{array}{c}\text { Present } \\
\left(\mathrm{km}^{2}\right)\end{array}$ & $\begin{array}{r}\text { With climate change } \\
\left(\mathrm{km}^{2}\right)\end{array}$ & $\begin{array}{c}\text { Change } \\
(\%)\end{array}$ \\
\hline Very high & 191.1 & 254.3 & 33.1 \\
High & 231.3 & 197.5 & -16.4 \\
Moderate & 104.9 & 112.1 & 6.9 \\
Low & 201.2 & 168.3 & -16.3 \\
\hline
\end{tabular}

would be a $60 \mathrm{~cm}$ sea-level rise by 2100 . However, the MARA failed to draw any conclusions on how climate change will influence inland flooding. The 2 climate models adopted by the MARA - the Canadian Climate Center (CCC) model and the Hadley model-produced different results for precipitation and runoff in this area: the CCC model projected substantial increases in precipitation and runoff by the year 2100,

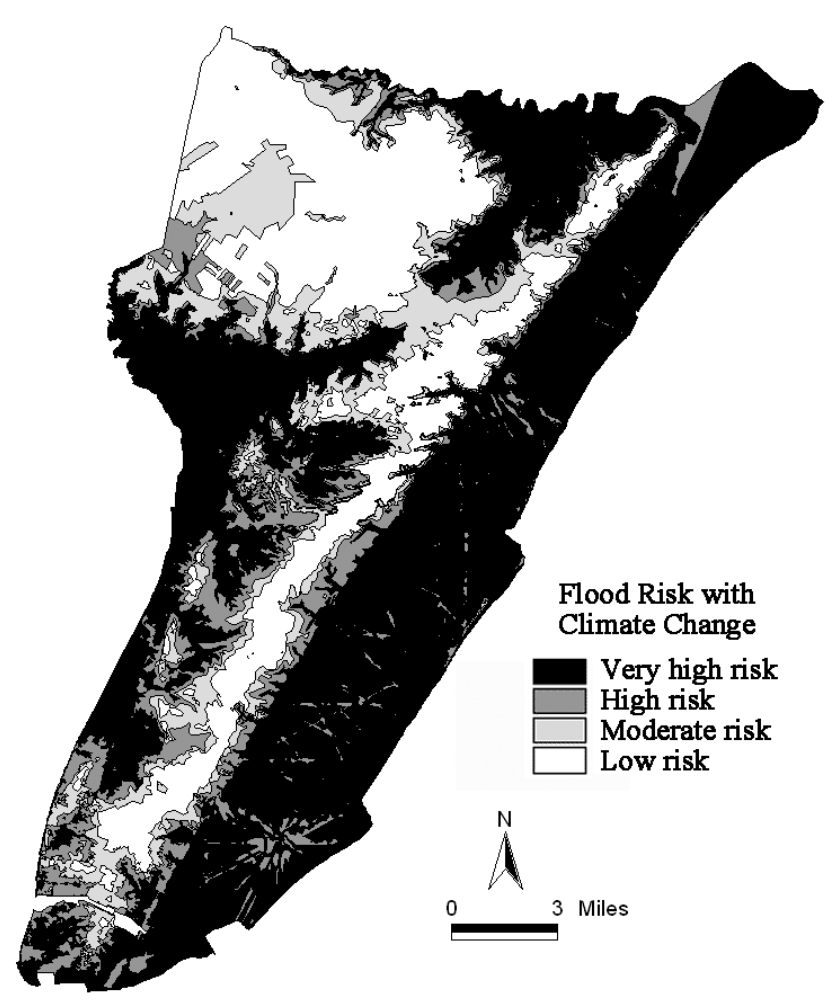

Fig. 4. Distribution of flood risk zones with climate change while the Hadley model projected a slight decrease in both variables (Fisher et al. 2000). Consequently, because riverine flooding is important to the county's potential risk of flooding, we include the present riverine flood risk as a constant when assessing future flood risk.

Fig. 4 shows the combined flood risk under climate change. To produce this figure, we applied the same procedure as that for mapping the present flood risk in Cape May County, but added $60 \mathrm{~cm}$ to the storm surge heights predicted by the SLOSH model. An argument can be made for inflating the $60 \mathrm{~cm}$ figure by as much as $50 \%$ because storm surge is not a simple addition to sea-level height, as wind-driven wave height grows with storm surge. Some storm surge models account for this factor for contemporary storm surges, but we opted to be conservative and not to include this factor into our future storm surge estimates. Even with such potential underestimation of the change in flood risk, Fig. 4 shows substantially more area at very high risk than today.

To highlight the differences between present and projected flood-risk zones, Fig. 5 shows changes between Figs. $3 \& 4$. The areas in red indicate the places presently exposed to high flood risk that would be exposed to very high flood risk with a $60 \mathrm{~cm}$ sea-level

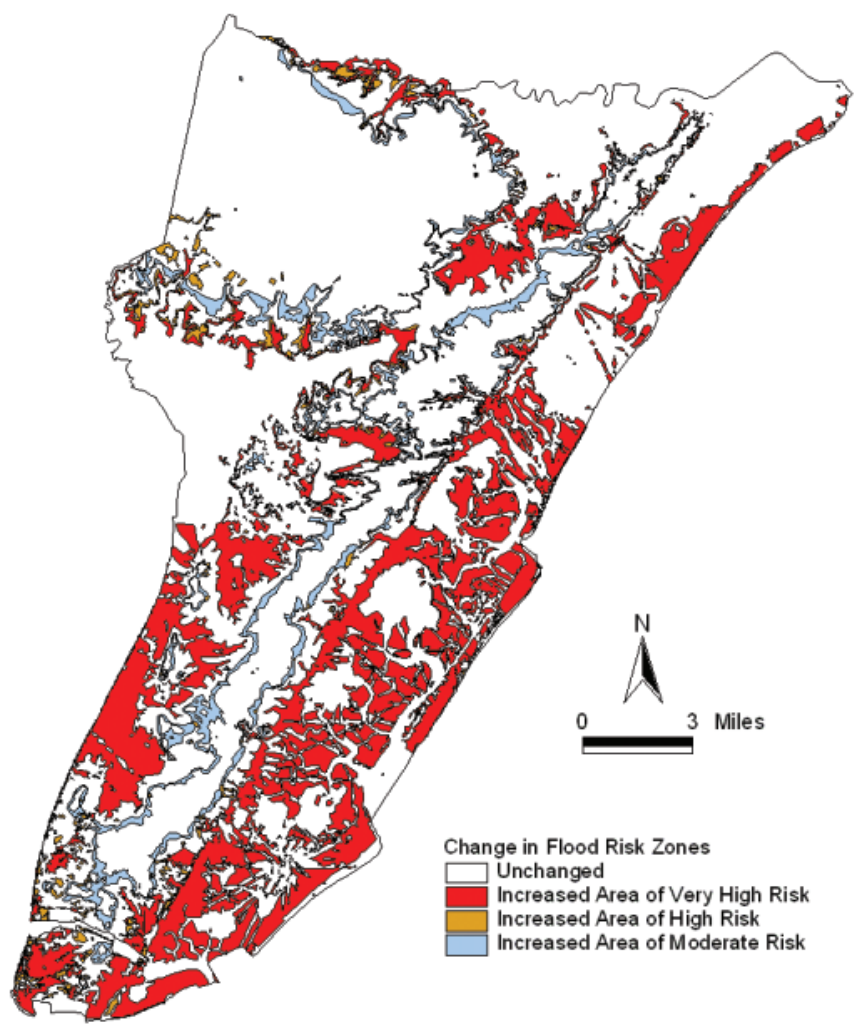

Fig. 5. Changes in flood risk zones 
rise. Table 8 complements Figs. $3-5$ by displaying the area for each risk category both for the present and with climate change. Notably, the area with very high flood risk would increase by $33 \%$ with a $60 \mathrm{~cm}$ sealevel rise. This scenario has important consequences for the county's vulnerability to flooding because many developed areas that today are situated in high-risk zones would be exposed to very high flood risk in the future.

\subsubsection{Land use}

A flood will not constitute a hazard unless it poses a risk to people's lives and property, or to other places they care about (such as wildlife habitat). A simple indication of a place's exposure to flood hazard is to compare its land use/land cover to the flood-risk zones. Cape May County's 'current' land-use patterns are shown in Fig. 2 and summarized in Table 9. They come from 1992 land-use/land-cover data provided by the United States Geological Survey (USGS) with a $30 \mathrm{~m}$ resolution. Over $45 \%$ of the county is covered with wetland and wooded wetland. Landward areas are mainly forested with scattered agricultural and developed areas. Although developed land accounts for only $15 \%$ of the county's total area, more than half of the development is concentrated on the barrier islands and areas immediately adjacent to either the Atlantic Ocean or the Delaware Bay. This land-use pattern indicates that a large percentage of the population and their property are at high risk of coastal flooding.

Although there are substantial uncertainties about future land uses, it is instructive to examine how the change in flood risk would affect the county's current land use patterns. Fig. 5 and Table 9 indicate that sealevel rise would greatly exacerbate the county's flood risk. Most significant, nearly $35 \%$ of the developed areas will be exposed to very high flood risk under the climate change scenario, compared with less than $10 \%$ today, representing a net increase of $25 \%$ of developed area at very high risk of flooding. On the one hand, this analysis may underestimate flood risk because it ignores the probable population increase in the next $100 \mathrm{yr}$ and hence the likelihood that there will be substantial pressure for development to continue in lowlying areas. On the other hand, vulnerability could be moderated by policies that direct development to more protected sites when infrastructure, housing, and businesses require replacement.

Currently, $50.5 \%$ of the county's wetland area, $14 \%$ of its forested wetland, and $67.9 \%$ of its beaches now are exposed to very high risk of flooding. These values would increase to $93.1 \%$ of total wetland, $40.7 \%$ of forested wetland, and $87.7 \%$ of beaches exposed to very high flood risk under the climate change scenario. Thus, sea-level rise would put significantly more of the county's ecosystems at risk of flooding.

\subsection{Social vulnerability}

The impacts of hazardous events such as flooding are not evenly distributed among and within communities. Drawing on a growing literature of vulnerability studies, Clark et al. (1998) define vulnerability to hazards as 'people's differential incapacity to deal with hazards, based on the position of the groups and individuals within both the physical and social worlds' (p. 59). Therefore, vulnerability is a function of both exposure and coping ability and is, hence, both physically and socially constructed. In the previous section, we examined how the physical exposure of Cape May County to flooding would change with sea-level rise. This section examines the social vulnerability of the county.

Table 9. Changes in the distribution of land-use types in flood-risk zones resulting from climate change

\begin{tabular}{|c|c|c|c|c|c|c|c|c|}
\hline \multirow[t]{2}{*}{ Land-use type } & \multicolumn{2}{|c|}{ Very high risk } & \multicolumn{2}{|c|}{ High risk } & \multicolumn{2}{|c|}{ Moderate risk } & \multicolumn{2}{|c|}{ Low risk } \\
\hline & $\begin{array}{c}\text { Area } \\
\text { change } \\
\left(\mathrm{km}^{2}\right)\end{array}$ & $\begin{array}{l}\text { Percent } \\
\text { change }\end{array}$ & $\begin{array}{l}\text { Area } \\
\text { change } \\
\left(\mathrm{km}^{2}\right)\end{array}$ & $\begin{array}{l}\text { Percent } \\
\text { change }\end{array}$ & $\begin{array}{c}\text { Area } \\
\text { change } \\
\left(\mathrm{km}^{2}\right)\end{array}$ & $\begin{array}{l}\text { Percent } \\
\text { change }\end{array}$ & $\begin{array}{c}\text { Area } \\
\text { change } \\
\left(\mathrm{km}^{2}\right)\end{array}$ & $\begin{array}{l}\text { Percent } \\
\text { change }\end{array}$ \\
\hline Agriculture & 2.6 & 7.1 & -0.8 & -2.0 & 1.6 & 4.0 & -3.4 & -9.1 \\
\hline Developed & 26.4 & 25.1 & -23.8 & -22.6 & 4.1 & 3.8 & -6.7 & -6.4 \\
\hline Forested wetland & 37.3 & 26.6 & -33.4 & -23.8 & 4.1 & 3.0 & -8.0 & -5.8 \\
\hline Barren/mines & 0.3 & 3.0 & 0.0 & -0.8 & 0.3 & 4.5 & -0.5 & -6.7 \\
\hline Beach & 1.0 & 19.8 & -1.0 & -18.0 & 0.0 & -1.9 & 0.0 & 0.0 \\
\hline Forest & 8.0 & 5.3 & -5.2 & -3.5 & 9.6 & 6.5 & -12.4 & -8.3 \\
\hline Wetland & 76.1 & 42.6 & -75.9 & -42.5 & 0.3 & 0.1 & -0.3 & -0.2 \\
\hline Open water & 7.5 & 9.1 & -7.5 & -9.0 & 0.3 & 0.2 & -0.3 & -0.3 \\
\hline Other & 0.0 & 5.8 & 0.0 & 14.3 & -0.3 & -17.0 & 0.0 & -3.1 \\
\hline Total & 159.2 & 22.5 & -147.6 & -20.8 & 20.0 & 2.8 & -31.6 & -4.5 \\
\hline
\end{tabular}


The fundamental causes of social vulnerability, such as certain cultural beliefs and norms and lack of access to resources and political power, vary greatly in time and space. Still, most research demonstrates that some demographic and housing characteristics-e.g. age, gender, race, income, and building quality-are influential in amplifying or reducing overall vulnerability to hazards (Blaikie et al. 1994, Cutter 1996, Hewitt 1997, Tobin \& Montz 1997, Clark et al. 1998, Cutter et al. 2000). Based on the existing literature, we examined the following variables:

- Total population

- Total housing units

- Number of females

- Number of non-white residents

- Number of people under 18

- Number of people over 60

- Number of female-headed single-parent housholds

- Number of renter-occupied housing units

- Median house value

While not fully explaining the underlying causes of the social vulnerability, these variables do provide an initial metric for operationalizing the concept (Cutter et al. 2000). All of the social data were taken from the 1990 US Census block statistics. ${ }^{1}$

Modified from the methodology adopted in Cutter et al. (2000), we calculated a vulnerability index for each census block and for each of the variables; we also compiled a composite social vulnerability index by combining the vulnerability indices of all variables. The vulnerability index for each social variable was defined as the ratio of the value of that variable in each census block $\left(V_{n}\right)$ to the maximum value ( $\left.V_{\max }\right)$ for the variable in the county:

$$
I_{\mathrm{n}}=\frac{V_{\mathrm{n}}}{V_{\max }}
$$

All the vulnerability indices were created in this manner with the exception of median house value. The vulnerability index for median house value was created in the following way:

$$
I_{\mathrm{n}}=1-\frac{V_{\mathrm{n}}}{V_{\max }}
$$

Standardized in the above ways, the vulnerability indices range from 0 to 1 ; higher index values indicate higher vulnerability. As we did not attach specific weights to individual variables, the composite social vulnerability index for each census block is defined as the arithmetic mean of the vulnerability indices of all

\footnotetext{
${ }^{1}$ At the time of the research, the 2000 Census data were not widely available, particularly the statistics at the block level, which is important for the spatial pattern of these variables in Cape May County
}

variables. The values were then placed into quartiles, labeled respectively as low, moderate, high, and very high according to their vulnerability index values, and displayed in Fig. 6. The map provides a broad overview of the spatial distribution of social vulnerability within the county. It shows that most of the barrier islands are socially vulnerable because of the higher concentration of elderly people. Among the barrier islands, Avalon and Stone Harbor have relatively lower social vulnerability because they are the wealthiest part of the county with the highest average income level and median house value. Away from the oceanfront, the most socially vulnerable areas tend to be located near larger towns such as Woodbine, Cape May Court House, and the Villas because of the higher concentration of non-white and poorer people in those areas.

\subsection{Present and future vulnerability of Cape May County}

We produced an overall flood vulnerability map for Cape May County by combining the flood hazard zones and the social vulnerability layer. The overall vulnerability index is defined as the product of regrouped flood hazard scores (1 to 4 ) and the social vulnerability index (0 to 1 ). The overall vulnerability scores are divided into quartiles, each quartile covering the same amount of land area. Using quartiles labeled as low, moderate, high, and very high, the left panel of Fig. 7 displays the spatial distribution of today's overall flood vulnerability in Cape May County.

We used the same procedure to derive the spatial distribution of flood vulnerability of Cape May County associated with future climate change (right panel of Fig. 7). Instead of developing new quartile cutoffs corresponding to the vulnerability scores under the climate change scenario, the quartile cutoff values of the present vulnerability scores are applied so that category changes related to climate change can be easily seen. The figure shows that sea-level rise will increase the overall flood vulnerability of the county. This increase can be quantitatively demonstrated by comparing the 2 sets of vulnerability index values (Table 10). The difference between the 2 sets of values is statistically significant, with a p-value of 0.00 in the Mann-Whitney test (The non-parametric Mann-Whitney test is used instead of a $t$-test because the vulnerability index values are not normally distributed). Comparison of the mean, median, and quartile values of the vulnerability scores indicates the magnitude of the increased vulnerability. Clearly, vulnerability index values under the climate change scenario are significantly higher than present-day values. 


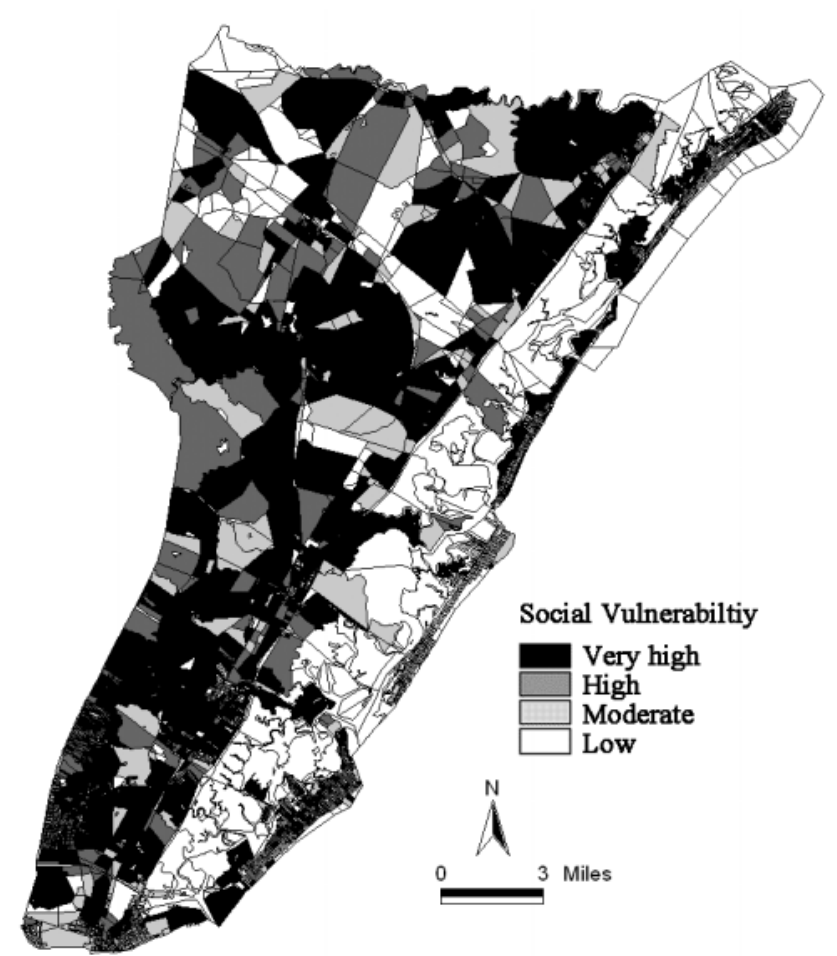

Fig. 6. Distribution of social vulnerability zones

In addition to the spatial representation of the overall vulnerability of Cape May County, we estimated the number of people and structures in each of the flood hazard zones and how that will change with projected
Table 10. Comparison between the present vulnerability index values and those under the climate change scenario

\begin{tabular}{|lcccc|}
\hline $\begin{array}{l}\text { Vulnerability } \\
\text { index }\end{array}$ & Mean & Median & $\begin{array}{c}\text { Upper } \\
\text { quartile }\end{array}$ & $\begin{array}{c}\text { Lower } \\
\text { quartile }\end{array}$ \\
\hline Present & 2.31 & 1.72 & 3.92 & 0.01 \\
With climate change & 2.62 & 2.06 & 4.55 & 0.02 \\
\hline
\end{tabular}

sea-level rise (Table 11). We used areal interpolation techniques when hazard zone boundaries cut across census blocks, assuming even distribution of population and structure within each of the blocks. Conspicuously, population exposed to very high flood risk will increase by $105 \%$ under the climate change scenario. Similar increases will happen with the total number of households and housing units, which is not surprising because these variables are highly correlated with population. Assuming the same population size and socioeconomic distribution, Table 11 also summarizes how climate change would affect each vulnerable subgroup. The proportion of vulnerable subgroups that would be exposed to higher flood risk increases significantly under the climate change scenario. As in the previous subsections, this analysis does not account for potential growth in population and where in the county such growth would occur. Therefore, it may underestimate future vulnerability of the county to flooding.
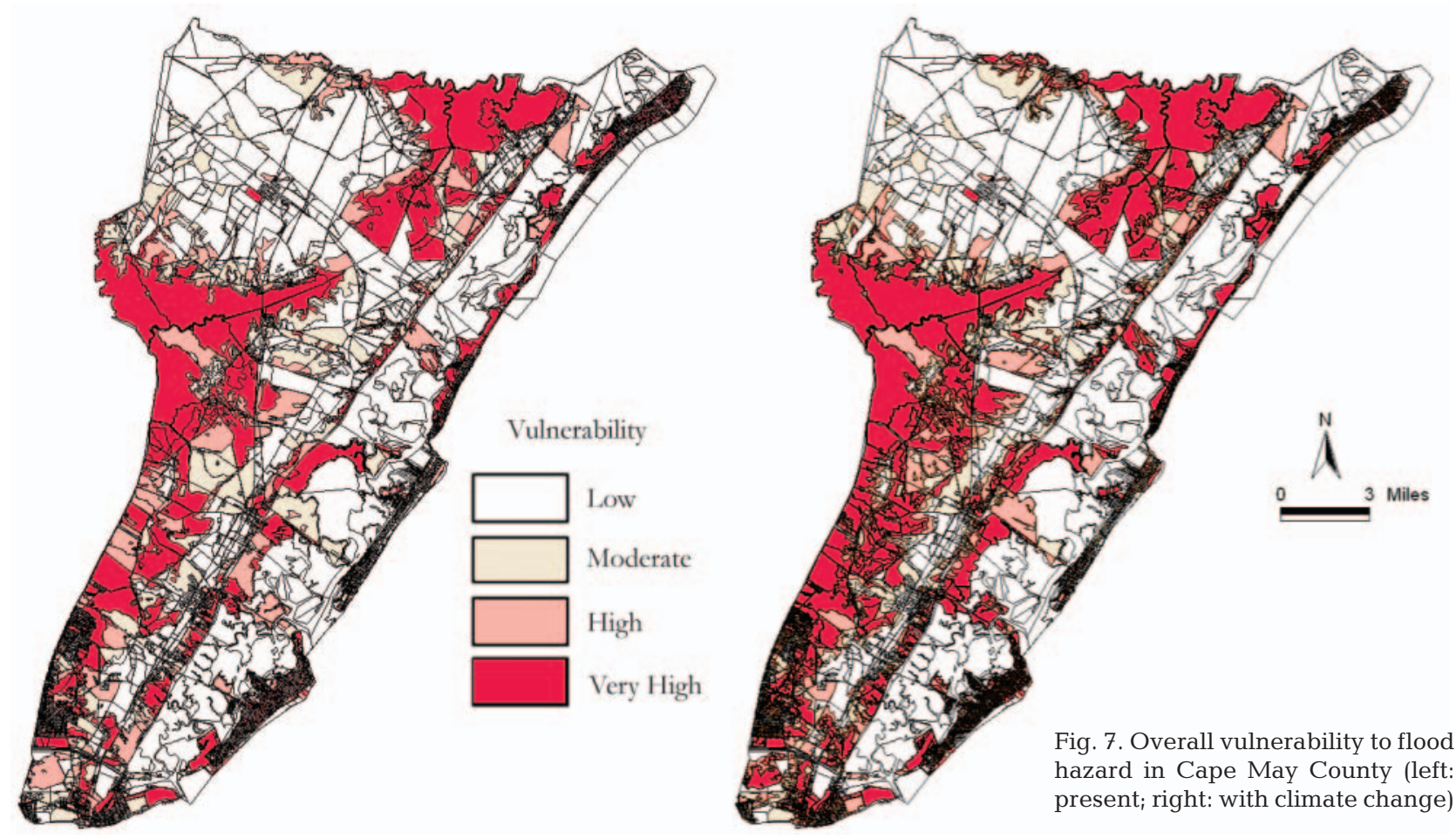
Table 11. Distribution of variables of social vulnerability with regard to flood-risk zones

\begin{tabular}{|c|c|c|c|c|c|c|}
\hline & \multirow{2}{*}{ Flood-risk zone } & \multicolumn{2}{|c|}{ Present } & \multicolumn{2}{|c|}{ With climate change } & \multirow{2}{*}{$\begin{array}{c}\text { Change } \\
\%\end{array}$} \\
\hline & & Number & $\%$ & Number & $\%$ & \\
\hline \multirow[t]{4}{*}{ Population } & Very high risk & 10358 & 10.8 & 21239 & 22.2 & 105.1 \\
\hline & High risk & 44080 & 46.0 & 37992 & 39.6 & -13.8 \\
\hline & Moderate risk & 14549 & 15.2 & 16059 & 16.8 & 10.4 \\
\hline & Low risk & 26865 & 28.0 & 20562 & 21.5 & -23.5 \\
\hline \multirow[t]{4}{*}{ Housing units } & Very high risk & 11161 & 13.0 & 23901 & 27.9 & 114.2 \\
\hline & High risk & 40808 & 47.7 & 35577 & 41.6 & -12.8 \\
\hline & Moderate risk & 12072 & 14.1 & 13225 & 15.5 & 9.5 \\
\hline & Low risk & 21500 & 25.1 & 12838 & 15.0 & -40.3 \\
\hline \multirow[t]{4}{*}{ Females } & Very high risk & 5637 & 11.3 & 11920 & 24 & 111.5 \\
\hline & High risk & 21916 & 44.0 & 19017 & 38 & -13.2 \\
\hline & Moderate risk & 7118 & 14.3 & 8124 & 16 & 14.1 \\
\hline & Low risk & 15098 & 30.3 & 10707 & 22 & -29.1 \\
\hline \multirow[t]{4}{*}{ Ethnic population } & Very high risk & 775 & 11.1 & 1221 & 17.4 & 57.5 \\
\hline & High risk & 2512 & 35.8 & 2345 & 33.4 & -6.7 \\
\hline & Moderate risk & 740 & 10.6 & 845 & 12.1 & 14.2 \\
\hline & Low risk & 2985 & 42.6 & 2601 & 37.1 & -12.8 \\
\hline \multirow[t]{4}{*}{ Young (under 18) } & Very high risk & 2107 & 9.9 & 4121 & 19.3 & 95.6 \\
\hline & High risk & 9438 & 44.3 & 8599 & 40.3 & -8.9 \\
\hline & Moderate risk & 4035 & 18.9 & 4574 & 21.5 & 13.4 \\
\hline & Low risk & 5735 & 26.9 & 4021 & 18.9 & -29.9 \\
\hline \multirow[t]{4}{*}{ Elderly (age over 60) } & Very high risk & 2995 & 12.0 & 5922 & 23.8 & 97.7 \\
\hline & High risk & 12906 & 51.9 & 11449 & 46.0 & -11.3 \\
\hline & Moderate risk & 3990 & 16.0 & 3921 & 15.8 & -1.7 \\
\hline & Low risk & 4974 & 20.0 & 3573 & 14.4 & -28.2 \\
\hline \multirow{4}{*}{$\begin{array}{l}\text { single-motner } \\
\text { households }\end{array}$} & Very high risk & 249 & 11.2 & 552 & 24.8 & 121.6 \\
\hline & High risk & 1080 & 48.4 & 875 & 39.2 & -19.0 \\
\hline & Moderate risk & 307 & 13.8 & 343 & 15.4 & 11.5 \\
\hline & Low risk & 595 & 26.7 & 461 & 20.7 & -22.5 \\
\hline Renter-occupied & Very high risk & 1590 & 14.9 & 3731 & 35.0 & 134.7 \\
\hline \multirow[t]{3}{*}{ housing units } & High risk & 6380 & 59.9 & 4542 & 42.6 & -28.8 \\
\hline & Moderate risk & 1138 & 10.7 & 1206 & 11.3 & 5.9 \\
\hline & Low risk & 1543 & 14.5 & 1172 & 11.0 & -24.0 \\
\hline
\end{tabular}

Finally, the survival of a community depends on the services provided by local facilities. Crucial facilities include hospitals, schools, nursing homes, fire and rescue departments, police, utilities, communication hubs, and transportation depots. The total number of these crucial facilities that are exposed to high flood risk can be used as an indicator of how vulnerable the community is to flooding. We obtained the integrated facility data from NJDEP, which was created through the assimilation of 13 different regulatory permit databases maintained by the department. We identified the critical facilities for the above-mentioned categories from the database and used the total number of these facilities as an indication of the community's vulnerability to flood hazard. Assuming no change in the location of these facilities, Table 12 summarizes the change in facilities located in the floodrisk zones. The analysis shows a significant increase $(157 \%)$ in the number of facilities that would be exposed to very high flood risk under the climate change scenario. Our assumption of no future increase in the number of critical facilities probably understates the increase in the vulnerability of these facilities to flood risk, but vulnerability could also be offset somewhat by relocation of these facilities to safer areas.

\subsection{Uncertainties and bounding scenarios}

The above vulnerability assessment ignored 2 important factors: the uncertainty in the projection of

Table 12. Number of critical facilities in different flood-risk zones

\begin{tabular}{|lrcr|}
\hline & $\begin{array}{c}\text { Present } \\
\text { number of } \\
\text { licensed } \\
\text { facilities }\end{array}$ & $\begin{array}{c}\text { Number of } \\
\text { licensed facilities } \\
\text { with climate } \\
\text { change }\end{array}$ & $\begin{array}{c}\text { Change } \\
(\%)\end{array}$ \\
\hline Very high risk & 51 & 131 & 156.86 \\
High risk & 121 & 45 & -62.81 \\
Moderate risk & 17 & 27 & 58.82 \\
Low risk & 79 & 65 & -17.72 \\
\hline
\end{tabular}


sea-level rise and the degree and pattern of future development in Cape May County. Consequently, this section examines how the results are affected by using 3 scenarios that incorporate the uncertainty of both sea-level rise and development, which we explain in the following paragraphs.

In the spirit of Schwartz (1991), and based on a few relatively well-established assumptions rather than the complete spectrum of uncertain factors, we explored the range of scenarios that could reasonably exist. The intent is to examine both positive and negative impacts of these 'what-if' scenarios and to reveal insights that might be helpful in community decisions.

According to the range provided by the MARA (Fisher et al. 2000), we used sea-level rise projections of 30,60 , and $90 \mathrm{~cm}$ for our scenarios for 2100. The size of the flood-risk zones under these scenarios is presented in Table 13 .

For development, we used scenarios based on projections of total population. We chose total population as the most important variable to represent future development because changes in other factors, such as facilities, housing units, and land-use patterns, are usually driven by-and highly correlated withpopulation growth. Moreover, it is the most important indicator for social vulnerability because many of the other socioeconomic indicators, such as gender and age category, usually correlate with total population. We considered 2 components of total population and developed scenarios for them: the absolute amount of population growth and the distribution of population growth. Projections of low, medium, and high absolute population growth are presented in Fig. 8 based on the NPA demographic projections dataset (NPA Data Services, Inc. 1998). ${ }^{2}$

Projecting the distribution of future population is not so straightforward. Cape May County is characterized both by great pressures for development and by vigorous regulations to manage such development, particularly along coastal frontages. One indication of development pressure is that the county's population has increased by $70 \%$ since 1970 (Fig. 8). Efforts to manage growth began with the New Jersey Coastal Area Facilities Review Act

\footnotetext{
${ }^{2}$ The NPA provided county-level demographic and economic projections to 2050 for the First National Assessment of the potential consequences of climate variability and change. We then extrapolated those projections to 2100
}

of 1973 (CAFRA), which empowers the state to protect the coastal environment, including scenic and aesthetic values. For areas covered by CAFRA, developers must ask the Coastal Zone Management Program, part of the Land Use Regulation Program of the New Jersey Department of Environmental Protection and Energy (DEP), for permits for industrial facilities and all residential development with 24 or more dwelling units. The permitting process includes a public hearing that affords project supporters and opponents an opportunity to argue whether an application realizes CAFRA guidelines (O'Connor et al. 1994). Therefore, because of the CAFRA process and the fact that most of the coastal frontages are built up, it is reasonable to think that future development in Cape May County is likely to happen mainly in inland areas where the flood risk is relatively low.

Given this knowledge, we constructed 3 population distribution scenarios. The high-risk scenario assumes that the future population would have the same distribution pattern as now. Given the existing restrictions on development and the likelihood that older high-risk structures would gradually be replaced by new structures farther inland, the high-risk scenario is the least likely. The medium-risk scenario assumes that population growth would happen mainly in low and moderate flood-risk zones and in the relatively lower-risk portion of the high flood-risk zone (i.e. people would develop in areas with a risk score of 6 or lower, but not in areas of score 7 or higher; refer to Tables $5-7$ ). The low-risk 
scenario assumes that all population growth would occur in low and moderate flood-risk zones.

Combining the high, medium, and low scenarios for sea-level rise, for population growth, and for population distribution, we produced 3 future impact scenarios, summarized in Table 14. While other combinations could be analyzed, our intent is to show credible upper and lower-bounds along with a realistic mid-range. The distributions of population in different flood-risk zones under these 3 future scenarios are presented in Table 15, together with the present-day distribution for comparison.

There would be a substantial increase in the population exposed to very high flood risk in the future. However, under the lower-bound scenario, the percentage of population exposed to very high flood risk would only increase from 10.8 to $13.8 \%$. Under this scenario, the percentage of people in both high and very high flood-risk zones would actually decrease from 56.8 to $47.8 \%$. The medium scenario shows similar results: there would be a slight increase in the percentage of total population that would be exposed to very high flood risk (from 10.8 to $14.2 \%$ ) and a slight decrease in the percentage of people in both the high and very high flood-risk zones (from 56.8 to $48.9 \%$ ). The upperbound scenario, however, presents a much different picture for the potential impacts of the sea-level rise on the county: the percentage of people exposed to very high flood risk would increase from 10.8 to $44.2 \%$, while the percentage of people exposed to high and very high flood risk would increase from 56.8 to $64.5 \%$. In short, there is potential for substantial increase in the county's vulnerability to coastal flooding with sealevel rise.

\section{CONCLUSIONS}

Climate change, particularly with its consequent sea-level rise, will have substantial impacts on the vulnerability of coastal communities to flooding. The case study of Cape May County shows that sea-level rise will increase the share of land areas exposed to high and very high flood risk. Such an increase will have important implications for the county. It will significantly increase the overall vulnerability of the county and will expose an increased number of critical facilities, properties, and people-particularly vulnerable subgroups - to the risk of flooding.

Despite this demonstrated increased exposure to risk, the study may well underestimate the increase in the county's vulnerability to flooding from climate change. This underestimation would occur if climate change resulted in increased inland flooding from heavier or more frequent extreme rainfall events, increased coastal storm frequency and intensity, and altered storm tracks that make local landfall more likely, all of which would exacerbate the county's vulnerability to flooding. The upper- and lower-bound future scenarios indicate that, on the one hand, poorly managed development could increase the county's vulnerability to flooding but, on the other hand, people could act to reduce vulnerability by making policy choices that steer development away from the higherrisk areas.

This study focused on direct human vulnerability to flooding. It ignored the potential impacts on the ecosystems of the county, which may not adapt as readily as people and their infrastructures. Yet, given the importance of ecosystems to the quality of life and to the economy of Cape May County, a comprehensive regional integrated assessment would include the positive and negative impacts of climate change and of development on the natural environment, as well as on the built environment.

Table 15. Present and future distribution of population in flood-risk zones

\begin{tabular}{|c|c|c|c|c|c|c|c|c|}
\hline \multirow[b]{2}{*}{ Scenario } & \multicolumn{2}{|c|}{ Low-risk zone } & \multicolumn{2}{|c|}{ Moderate-risk zone } & \multicolumn{2}{|c|}{ High-risk zone } & \multicolumn{2}{|c|}{ Very high-risk zone } \\
\hline & No. & $\%$ & No. & $\%$ & No. & $\%$ & No. & $\%$ \\
\hline Present & 26865 & 28.0 & 14549 & 15.2 & 44080 & 46.0 & 10358 & 10.8 \\
\hline Lower bound & 38450 & 31.6 & 24994 & 20.6 & 41304 & 34.0 & 16753 & 13.8 \\
\hline Medium & 42709 & 28.6 & 33356 & 22.4 & 51795 & 34.7 & 21239 & 14.2 \\
\hline Upper bound & 49078 & 18.5 & 44931 & 16.9 & 53838 & 20.3 & 117295 & 44.2 \\
\hline
\end{tabular}


Acknowledgements. We thank our colleagues on the MidAtlantic Regional Assessment (MARA) and Human-Environment Regional Observatory (HERO) projects, especially Jim Shortle and Bob O'Connor, for their help on the research. We also thank the 3 anonymous reviewers for their constructive critiques of this paper. This material is based on work supported by the US Environmental Protection Agency under Cooperative Agreement No. CR826554-01 (A.F., Principal Investigator) and by the National Science Foundation under Grant No. SBE-9978052 (B.Y., Principal Investigator). Any opinions, findings and conclusions or recommendations expressed in this material are those of the authors and do not necessarily reflect those of the US Environmental Protection Agency or the National Science Foundation.

\section{LITERATURE CITED}

Alexander D (1993) Natural disasters. Chapman \& Hall, New York

Alexander D (1997) The study of natural disasters, 1977-1997: some reflections on a changing field of knowledge. Disasters 21:284-304

Anderson MB, Woodrow PJ (1991) Reducing vulnerability to drought and famine: developmental approaches to relief. Disasters 15:43-54

Bentley M, Horstmeyer S (1999) Hurricane legacies: the impacts of three historic storms went far beyond the headlines. Weatherwise 52(5):28-32

Blaikie P, Brookfield H (1987) Land degradation and society. Methuen, London

Blaikie P, Cannon T, Davis I, Wisner B (1994) At risk: natural hazards, people's vulnerability, and disasters. Routledge, London

Bogard WC (1989) Bringing social theory to hazards research: conditions and consequences of the mitigation of environmental hazards. Sociol Perspect 31:147-168

Bohle HG, Downing TE, Watts MJ (1994) Climate change and social vulnerability: the sociology and geography of food insecurity. Global Environ Change 4:37-48

Bolin R, Bolton P (1986) Race, religion, and ethnicity in disaster recovery. Institute of Behavioral Science, University of Colorado, Boulder

Bolin R, Klenow D (1983) Response of the elderly to disaster: an age-stratified analysis. Int J Aging Human Develop 16:283-296

Bolin R, Stanford L (1991) Shelter, housing, and recovery: a comparison of US disasters. Disasters 15:24-34

Chambers R (1989) Vulnerability, coping and policy. IDS Bull 29:1-7

Chen RS (1994) The human dimension of vulnerability. In: Socolow R, Andrews C, Berkhout F, Thomas V (eds) Industrial ecology and global change. Cambridge University Press, Cambridge, p 85-105

Clark G, Moser S, Ratick S, Dow K and 6 others (1998) Assessing the vulnerability of coastal communities to extreme storms: the case of Revere, MA, USA. Mitig Adapt Strat Global Change 3:59-82

Cobb HD III (1991) The Chesapeake-Potomac hurricane of (1933) Weatherwise 44(4):24-29

Cutter SL (1996) Vulnerability to environmental hazards. Prog Human Geogr 20(4):529-539

Cutter SL, Mitchell JT, Scott MS (2000) Revealing the vulnerability of people and places: a case study of Georgetown County, South Carolina. Ann Assoc Am Geogr 90:713-737

David SD, Baish S, Morrow BH (1999) Uncovering the hidden costs of coastal hazards. Environment 41(8):10-19
Davis RE, Dolan R (1992) The 'All Hallows' Eve storm - October 1991. J Coastal Res 8:978-983

Davis RE, Dolan R (1993) Nor'easters. Am Sci 81:428-439

Degg M (1993) Earthquake hazard, vulnerability and response. Geography 78:165-170

Dolan R, Davis RE (1992) An intensity scale for Atlantic Coast northeast storms. J Coastal Res 8:840-853

Dolan R, Lins H, Hayden B (1988) Mid-Atlantic coastal storms. J Coastal Res 4:417-433

Dolan R, Inman DL, Hayden B (1990) The Atlantic coast storm of March 1989. J Coastal Res 6:721-725

Dow K (1992) Exploring differences in our common future(s): the meaning of vulnerability to global environmental change. Geoforum 23(3):417-436

Dow K, Downing TE (1995) Vulnerability research: where things stand. Human Dimensions Q 1:3-5

Downing TE (1991) Vulnerability to hunger and coping with climate change in Africa. Global Environ Change 1: 365-380

Downing TE (1992) Climate change and vulnerable places: global food security and county studies in Zimbabwe, Kenya, Senegal and Chile. Research Report 1. Environmental Change Unit, University of Oxford

Drabek T, Key W (1986) Conquering disaster: family recovery and long-term consequences. Irvington, New York

Elsner JB, Kara A (1999) Hurricanes of the North Atlantic: climate and society. Oxford University Press, New York

Enarson E, Morrow B (1998) The gendered terrain of disaster. Praeger, New York

FEMA (1996) Federal Emergency Management Agency National Flood Insurance Program Q3 Flood data. Discussion 18, FEMA Region 3, New York

Fisher A, Abler D, Barron E, Bord R and 9 others (2000) Preparing for a changing climate: the potential consequences of climatic variability and change. mid-Atlantic overview. The US Environmental Protection Agency, Washington, DC, and The Pennsylvania State University, University Park

Fothergill A, Meastas E, Darlington J (1999) Race, ethnicity and disasters in the United States: a review of literature. Disasters 23(2):156-173

Green CH (1990) Hazard and vulnerability analysis. Flood Hazard Research Centre, Middlesex Polytechnic, Enfield

Guard C, Lander MA (1999) The Saffir-Simpson hurricane scale. Water and Energy Research Institute, University of Guam, Mangilao; available at www.typhoon2000.ph/ tropical_SS.htm

H. John Heinz III Center for Science, Economics and the Environment (2000) The hidden costs of coastal hazards: implications for risk assessment and mitigation. Island Press, Washington, DC

Haque CE, Blair D (1992) Vulnerability to tropical cyclones: evidence from the April 1991 cyclone in coastal Bangladesh. Disasters 16:217-229

Hewitt K (ed) (1983) Interpretation of calamity. Allen \& Unwin, Winchester, MA

Hewitt K (1997) Region of risk: a geographical introduction to disasters. Longman, Harlow

Hewitt K, Burton I (1971) The hazardousness of a place: a regional ecology of damaging events. University of Toronto

Heyman BN, Davis C, Krumpe PF (1991) An assessment of worldwide disaster vulnerability. Disaster Manag 4:3-14

Hurricanecity (2001) Cape May's history with tropical systems. Hurricanecity: Info for Cities Threatened with Atlantic Hurricanes; available at www.hurricanecity.com/capemay.htm

IPCC (1996) Climate change 1995: economic and social dimensions of climate change. Cambridge University Press, Cambridge 
IPCC (1998) The regional impacts of climate change: an assessment of vulnerability. Cambridge University Press, Cambridge

IPCC (2001) Summary for policymakers: climate change 2001: impacts, adaptation, and vulnerability. A report of Working Group II of the Intergovernmental Panel on Climate Change; available at www.ipcc.ch/pub/ wg2SPMfinal.pdf

Leatherman S (2001) Social and economic costs of sea level rise. In: Douglas B, Kearney M, Leatherman S (eds) Sea level rise: history and consequences. Academic Press, San Diego, p 181-223

Lewis J (1987) Risk, vulnerability, and survival: some postChernobyl implications of people, planning, and civil defense. Local Gov Stud 13(4):75-93

Lewis J (1990) The vulnerability of small island states to sea level rise: the need for holistic strategies. Disasters 14(3):241-249

Liverman DM (1986) The vulnerability of urban areas to technological risks. Cities (May):142-147

Liverman DM (1990a) Vulnerability to global environmental change. In: Kasperson RE, Dow K, Golding D, Kasperson JZ (eds) (1990) Understanding global environmental change: the contributions of risk analysis and management. Earth Transformed Program, Clark University, Worcester, MA

Liverman DM (1990b) Drought in Mexico: climate, agriculture, technology and land tenure in Sonora and Puebla. Ann Am Assoc Geogr 80:49-72

Longhurst R (1995) The assessment of community vulnerability in hazard prone areas, conference report. Disasters 19:269-270

Ludlum DM (1963) Early American hurricanes 1492-1870. The American Meteorological Society, Boston

Mileti D (1999) Disasters by design: a reassessment of natural hazards in the United States. The Joseph Henry Press, Washington, DC

Mitchel JK, Devine N, Jagger K (1989) A contextual model of natural hazard. Geogr Rev 79: 391-409

Morrow BH (1999) Identifying and mapping community vulnerability. Disasters 23:1-18

Najjar RG, Walker HA, Anderson PJ, Barron EJ and 12 others (2000) The potential impacts of climate change on the mid-Atlantic coastal region. Clim Res 14:219-213

National Hurricane Center (NHC) (1999a) The Saffir-Simpson hurricane scale. Available at www.nhc.noaa.gov/aboutsshs. html

National Hurricane Center (NHC) (1999b) Hurricane awareness: storm surge. Available at www.nhc.noaa.gov/ HAW/ day1/storm_surge.htm

Nordstrom KF (2000) Beaches and dunes of developed coasts. Cambridge University Press, Cambridge

Nordstrom K, Gares P, Psuty N, Pilkey O, Jr, Neal W, Pilkey O,

Editorial responsibility: Andrew Comrie,

Tuscon, Arizona, USA
Sr (1986) Living with the New Jersey shore. Duke University Press, Durham, NC

NPA Data Services, Inc. (1998) Regional economic projections series. NPA Data Services, Washington, DC

O'Connor R, Bord R, Pflugh K (1994) The two faces of coastal environmentalism: environmental protection and development in Cape May. Coastal Manage 22:183-194

Palm RI, Hodgson ME (1992) Earthquake insurance: mandated disclosure, and homeowner response in California. Ann Assoc Am Geogr 82:207-222

Parr A (1987) Disasters and disabled persons: an examination of the safety needs of a neglected minority. Disasters 11:148-159

Quarantelli E (1991) Patterns of sheltering and housing in American disasters. Preliminary Paper no. 170. Disaster Research Center, University of Delaware, Newark

Quarantelli E (1992) Urban vulnerability and technological hazards in developing societies. Article 236. Disaster Research Center, University of Delaware, Newark

Savadore L, Bucholz MT (1993) Great storms of the Jersey shore. Down The Shore Publishing, Harvey Cedars, NJ

Schwartz P (1991) The art of the long view. Doubleday, New York

Susman P, O'Keefe P, Wisner B (1983) Global disasters, a radical interpretation. In: Hewitt $\mathrm{K}$ (ed) Interpretation of calamity. Allen \& Unwin, Boston, p 263-283

Tobin G, Montz B (1997) Natural hazards: explanation and integration. Guilford Press, New York

UNDRO (1977) Disaster prevention and mitigation: a compendium of current knowledge - land use aspects, Vol 5. UNDRO, New York

US Army Corps of Engineers (2001) Demonstration site: Cape May, New Jersey. Section 227, National Shoreline Erosion Control Development and Demonstration Program, US Army Corps of Engineers, Philadelphia District, Philadelphia. Available at: http://limpet.wes.army.mil/sec227/Demosites/capemay.htm

Walker HJ, Coleman JM (1987) Atlantic and Gulf coastal province. In: Graf WL (ed) Geomorphic systems of North America, Centennial Special Vol 2. Geological Society of America, Boulder, CO, p 51-110

Watson S (2001) March 1962 'Ash Wednesday' storm. Special reports: storms of the century. Report no. 9. Available at: www.weather.com/newscenter/specialreports/sotc/storm9/ page1.html

Watts MJ, Bohle HG (1993) The space of vulnerability: the causal structure of hunger and famine. Prog Human Geogr 17:43-67

Wilhite D, Easterling W (eds) (1987) Planning for drought: towards a reduction of societal vulnerability. Westview Press, Boulder

Yarnal B (1994) Socioeconomic restructuring and vulnerability to environmental hazards in Bulgaria. Disasters 8: 95-106

Submitted: July 18, 2001; Accepted: April 16, 2002

Proofs received from author(s): August 26, 2002 